\title{
Sonic Hedgehog and Bone Morphogenetic Protein-4 Signaling Pathway Involved in Epithelial Cell Renewal along the Radial Axis of the Intestine
}

\author{
Atsuko Ishizuya-Oka Takashi Hasebe \\ Department of Biology, Nippon Medical School, Kawasaki, Kanagawa, Japan
}

\section{Key Words}

Intestine $\cdot$ Stem cell $\cdot$ Regeneration $\cdot$ Apoptosis $\cdot$ Sonic

hedgehog $\cdot$ Thyroid hormone

\begin{abstract}
The organogenesis of the digestive tract proceeds according to the positional information along the cephalo-caudal, dorsal-ventral and left-right axes of the embryonic body and the radial axis of the tract during development. Among them the radial axis, which corresponds to the crypt-villus axis in the adult small intestine, is essential for a rapid cell renewal of the epithelium throughout adulthood and is important from the clinical viewpoint. All of the adult intestinal epithelial cells originate from multipotent stem cells localized in the basal region of the crypt. Descendants of the stem cells, as they migrate up or down along the crypt-villus axis, actively proliferate, differentiate and finally undergo apoptosis. Recently, there has been a growing body of evidence that the Wnt and Notch signaling pathways are involved in cell proliferation and cell fate determination, respectively, during the epithelial cell renewal. However, the molecular mechanisms by which the radial axis is established and/or is maintained to enable the epithelial cell renewal have not yet been fully understood, and their clarification is urgently needed for stem cell therapies. In the amphibian intestine during metamorphosis, stem cells analogous to the mammalian ones appear and newly form the epithelium that un-
\end{abstract}

dergoes the cell renewal along the radial axis by the inductive action of thyroid hormone. Thus, this animal model provides us with a good opportunity to clarify the molecular mechanisms of radial axis formation. By using the Xenopus laevis intestine, we found that sonic hedgehog (Shh), which is secreted by the stem cells, induces bone morphogenetic protein-4 (BMP-4) in subepithelial fibroblasts and that both Shh and BMP-4 are involved in the development of the cellrenewable epithelium. In this review, we highlight the molecular aspects of the cell renewal of the adult intestinal epithelium and propose important roles of the Shh/BMP-4 signaling pathway in the establishment and/or maintenance of the radial axis common to the human intestine.

Copyright $\odot 2008$ S. Karger AG, Basel

\section{Introduction}

It is well known that the epithelial cells of the small intestine rapidly undergo renewal throughout adulthood. Its multipotent stem cells reside in the specific region of the crypt just above and/or between Paneth cells and proliferate. Most of their descendants, as they migrate up along the crypt-villus axis, differentiate into major absorptive cells, goblet cells and enteroendocrine cells. Eventually, they degenerate through apoptosis at the tip of the villi. On the other hand, a small number of the other cells migrate down and differentiate into the $\mathrm{Pa}$ -

\section{KARGER}

Fax +41 613061234

E-Mail karger@karger.ch

www.karger.com
(C) 2008 S. Karger AG, Basel

0012-2823/08/0775-0042\$24.50/0

Accessible online at:

www.karger.com/dig
Atsuko Ishizuya-Oka

Department of Biology

Nippon Medical School

Kawasaki, Kanagawa 211-0063 (Japan)

Tel. +81 44733 3580, Fax +81 44722 1231, E-Mail a-oka@nms.ac.jp 
neth cells $[1,2]$. Thus, the cell renewal is regulated by positional information along the crypt-villus axis, which is called the 'radial axis' of the gut in developmental biology [3]. The disruption of the axis results in loss of control of cell proliferation, differentiation and/or apoptosis of the epithelium and leads to diseases such as cancer. Although the expression of numerous signaling molecules has been previously shown to be localized along the crypt-villus axis [4], only fragmentary information is available on their functions in the regulation of the axis and their mutual interactions in the whole set of signals. The amphibian intestinal remodeling, where the axis analogous to the mammalian crypt-villus one is established by the inductive action of thyroid hormone (TH), serves as a unique and excellent model for the study in this field. In the present review, we start with the outline of the regionally regulated development of the small intestine along the 4 axes and then describe what signaling molecules are known so far to be involved in the crypt-villus axis of the human small intestine. Finally, we review our recent findings on the molecular mechanisms by which the radial axis is established using the Xenopus amphibian intestine as an experimental model and propose conserved important roles of the sonic hedgehog (Shh) and bone morphogenetic protein-4 (BMP-4) signaling pathway in the regulation of the radial axis.

\section{Development of Small Intestine Progresses along the Axes}

The primitive gut during embryogenesis originates from the 3 germ layers. The embryonic endoderm, mesoderm and ectoderm differentiate into the intestinal epithelium, the mesenchyme that further differentiates into the connective tissue (the lamina propria and the submucosa) and muscles (the muscularis mucosa, and inner and outer muscles), and neural plexuses, respectively (fig. 1). The organogenesis of the gut is generally known to be regionally regulated by positional information along the 4 major axes, that is, the cephalo-caudal (CC), dorsal-ventral (DV), left-right (LR) and the radial axes. Among them the CC axis of the embryonic body is established during early development by signaling molecules including fibroblast growth factors and subsequently specified by homeobox genes such as Hox cluster genes and $C d x$ genes $[3,5]$. Along the $\mathrm{CC}$ axis the primitive gut is initially patterned into the fore-, mid- and hindguts. Then, each gut is further patterned along the CC axis and is differentiated into various digestive organs.

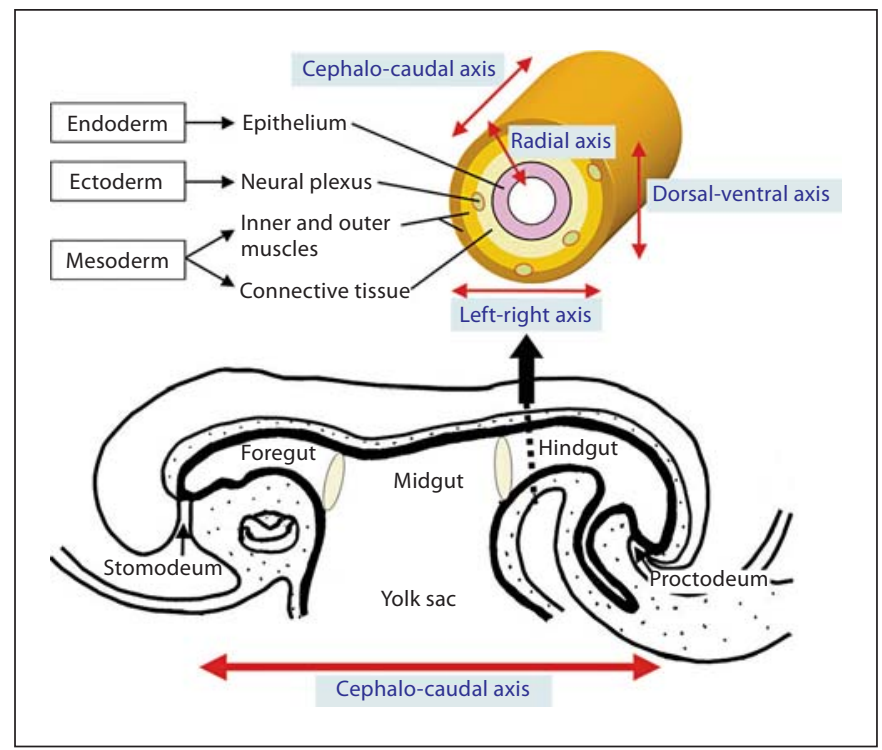

Fig. 1. Development of the digestive tract during human embryogenesis. Organogenesis of the digestive tract progresses along the 4 axes; the cephalo-caudal, dorsal-ventral, left-right and radial axes. The radial axis in the adult small intestine is called the crypt-villus axis and is essential for the epithelial cell renewal.

In addition, the other 3 axes are involved in the organogenesis of the primitive gut [3]. The foregut needs positional information along the DV axis to induce the endodermal budding, leading to the organogenesis of the pancreas and the liver.

Recently, there has been a growing body of evidence that $P d x-1$ (pancreatic and duodenal homeobox gene-1) plays a key role in development of the pancreatic epithelium along the DV axis. On the other hand, the LR axis of the body controls LR asymmetry in the gut such as the direction of the gastrointestinal rotation. The LR axis is generally known to be controlled by the restricted expression of Shh to the left side of the embryos, which starts a cascade of unilateral expression of genes including Nodal and Pitx.

Finally, the radial axis that is pattered from the outside to the inside of the gut is established later during development and is maintained throughout adulthood. In the adult small intestine the radial axis corresponds to 'the crypt-villus axis', and along this axis the epithelium undergoes a rapid cell renewal $[1,4]$. Although this axis is the most important from the clinical viewpoint, compared to the other 3 axes, little is known about what signaling molecules control this axis. 


\section{Epithelial Cell Renewal along the Radial Axis in the Adult Small Intestine}

In the adult small intestine, it is generally known that the microenvironment around the stem cells, called the 'niche', plays important roles in the epithelial cell renewal $[6,7]$. Structurally, the stem cell niche mainly consists of subepithelial myofibroblasts, which secrete various factors including extracellular matrix components, growth factors, cytokines, Wnt and epimorphin $[8,9]$. In addition, the vasculature endothelial cells, intraepithelial lymphocytes and enteric neurons distributed near the stem cells have been proposed as the niche players $[10,11]$, although the information on the molecules secreted by these cells has been only fragmentary. On the other hand, recent studies identified a number of signaling molecules whose localization is associated with the crypt-villus axis $[4,12]$. Although their functions have not yet been clarified enough, a growing body of evidence has shown that the Wnt and Notch signaling pathways play important roles in the epithelial cell renewal.

Wnt protein, which is secreted by the myofibroblasts in the crypt, activates the Wnt pathway by stimulating the binding of $\mathrm{T}$ cell factor- 4 to $\beta$-catenin. The $\beta$-cate$\mathrm{nin} / \mathrm{T}$ cell factor- 4 complex leads to the upregulation of the expression of target genes. In contrast, the adenomatous polyposis coli protein is known to compete with $\mathrm{T}$ cell factor- 4 to bind to $\beta$-catenin and suppresses the Wnt pathway [13]. Recently, a number of target genes have been identified in the adult intestine. They include c- $M y c$, which stimulates cell proliferation, $E p h B$, which is involved in cell migration, and $C d x-1$, which regulates endodermal differentiation in the embryonic gut and has pro-oncogenic potential in the adult intestine $[2,13]$.

On the other hand, the Notch signaling pathway generally affects cell fate decisions by lateral inhibition in cell-to-cell interactions through its receptor Delta. In the intestine, the stem cells highly express Notch, which inhibits the expression of Math-1 through the upregulation of Hes-1, a transcriptional repressor. Cells without Math1 expression remain as stem cells or can differentiate into absorptive cells, whereas cells expressing Math-1 differentiate into the secretory cells, that is, the enteroendocrine cell, goblet cell and Paneth cell lines [14]. Compared to the Wnt and Notch signaling pathways, little is known about the functions of other signaling pathways. The molecular mechanisms that control the crypt-villus axis of the small intestine remain poorly understood.

\section{Amphibian Intestinal Model for the Study of the Radial Axis}

Amphibian metamorphosis mimics the evolutionary process of transition from aquatic to terrestrial life and bears many similarities to the postnatal organ development in mammals [15]. In the amphibian small intestine during metamorphosis, most of the larval epithelial cells undergo apoptosis, whereas a small number of stem cells expressing Musashi-1, a candidate marker for the mammalian intestinal stem cells, appear and actively proliferate [16]. Then, with the progress of the intestinal fold formation, descendants of the stem cells differentiate into the adult intestinal epithelium analogous to the mammalian one (fig. 2). The amphibian adult epithelium after metamorphosis acquires a cell renewal system along the trough-crest axis of the intestinal folds similar to the crypt-villus axis in the mammalian intestine and consists of all cell types of the mammalian intestinal epithelium except for the Paneth cells [17].

Such similarities of the structures of the adult amphibian intestine to the mammalian ones suggest conserved mechanisms underlying the intestinal epithelial cell renewal.

The advantage of using the amphibian model is that the intestinal remodeling during metamorphosis can be completely controlled by TH through TH receptors. Here, the entire processes leading to the establishment of the radial axis can be clarified through the expression and functional analysis of TH response genes. From the 1990s, a number of $\mathrm{TH}$ response genes have been isolated from the Xenopus laevis intestine by using PCR-based subtractive differential screening [15]. Therefore, the amphibian intestine provides us with a unique and good opportunity for studying how the radial axis is established at the molecular level. By the expression analysis of such $\mathrm{TH}$ response genes, we have shown that Shh and BMP-4 correlate well with the development of the adult intestinal epithelium originating from the stem cells. Moreover, their functional analysis in vitro has shed light on the key roles of the Shh/BMP-4 signaling pathway in the establishment and/or maintenance of the radial axis [18].

\section{Shh and BMP-4 Signaling Pathway}

Recently, there has been a growing body of evidence that the Shh and BMP-4 signaling pathways play important roles in not only the organogenesis of the embryonic gut but also the homeostasis of the adult mammalian small intestine [19-21]. In fact, mutations in the members of these pathways have been associated with various mal- 
Fig. 2. Amphibian intestinal remodeling during metamorphosis and adult mammalian adult intestine. During intestinal remodeling, $\mathrm{TH}$ directly upregulates the expression of Shh in the stem cells. Shh promotes the proliferating activity of connective tissue cells and induces subepithelial fibroblasts to express BMP-4, which in turn represses its proliferative activity. In addition, BMP-4 promotes differentiation of the intestinal epithelium. BMP-4 activity may be regulated by BMP-1 through chordin. The adult amphibian intestine after remodeling undergoes cell renewal along the radial axis similar to the mammalian one. $\mathrm{RXR}=$ Retinoid $\mathrm{X}$ receptor; $\mathrm{TR}=\mathrm{TH}$ receptor.

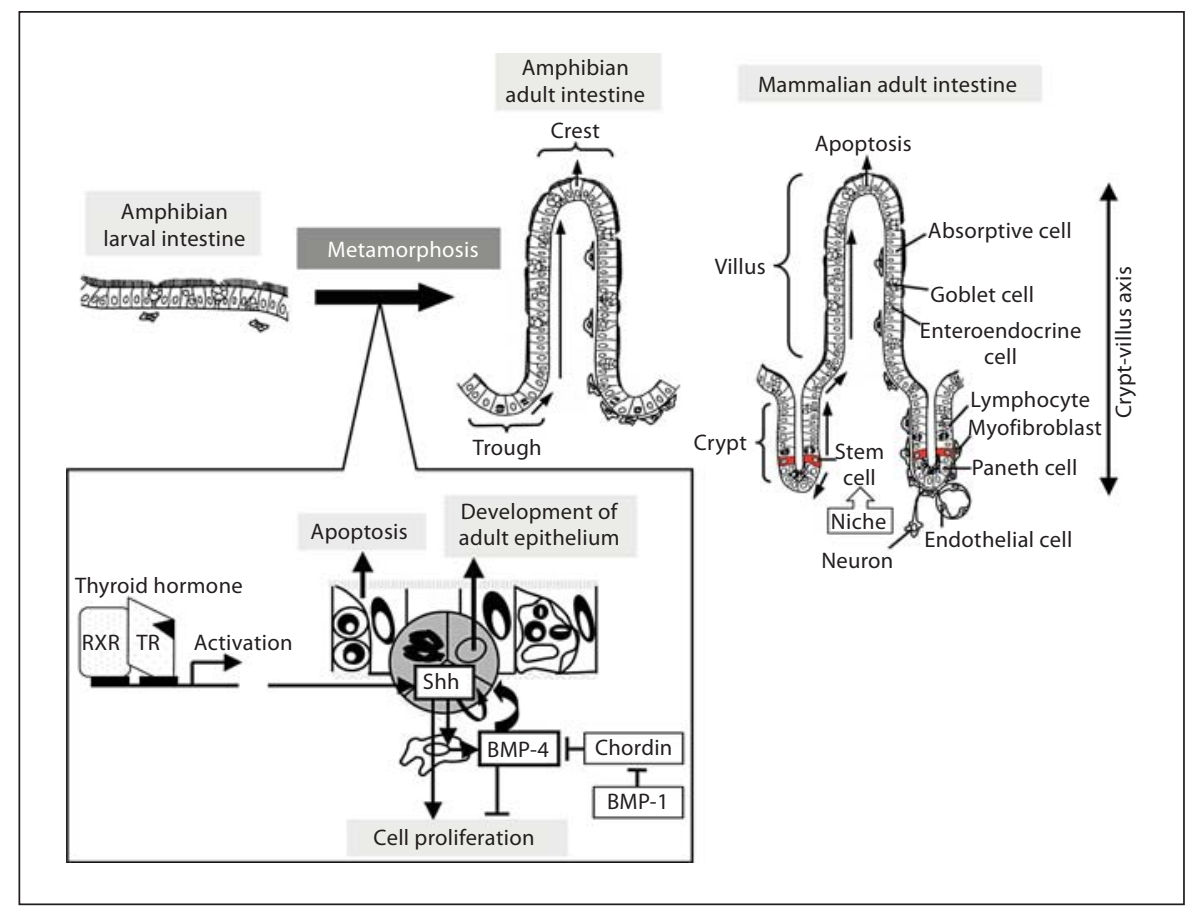

Table 1. Expression of Shh and BMP-4 and diseases associated with their signaling pathways in the digestive tract

\begin{tabular}{|c|c|c|c|}
\hline \multirow{2}{*}{$\begin{array}{l}\text { Signaling } \\
\text { molecules }\end{array}$} & \multicolumn{2}{|l|}{ Expression [19] } & \multirow[t]{2}{*}{ Malformations and diseases $[21,22]$} \\
\hline & embryonic gut & adult small intestine & \\
\hline Shh & endoderm & epithelial stem cell & $\begin{array}{l}\text { tracheoesophageal fistula } \\
\text { anal atresia }\end{array}$ \\
\hline BMP-4 & mesoderm & fibroblast & $\begin{array}{l}\text { juvenile polyposis syndrome } \\
\text { hypertrophic pyloric stenosis } \\
\text { Hirschsprung's disease }\end{array}$ \\
\hline
\end{tabular}

formations and diseases such as precancerous juvenile polyposis syndrome [21, 22] (table 1).

However, their precise function in the adult intestine has not yet been well documented at the molecular level. In the Xenopus intestine, Shh expression is directly and early upregulated in the epithelium by $\mathrm{TH}$. The highest expression of Shh is localized in the stem cells when they first appear and most actively proliferate during the intestinal remodeling [23]. In contrast, BMP-4 expression is highest in the subepithelial fibroblasts surrounding the stem cells. Using the organ culture of the Xenopus tadpole intestine, we have shown that Shh protein can induce BMP-4 expression only in fibroblasts [18], similar to the case in the avian gut during embryogenesis, where the endoderm-specific expression of Shh induces BMP-4 expression in the mesenchyme $[24,25]$. In the mammalian intestine, Shh is first expressed in the endoderm during embryogenesis and then, with the progress of the morphogenesis of villi, Shh expression becomes localized in the intervillus region, that is, the precrypt region, where stem cells will be localized [26]. Similarly, in the human adult intestine, Shh expression is reported to be localized in the stem cells [19]. Our culture studies using the amphibian model strongly suggest that $\mathrm{Sh} h$, which is generally secreted by the stem cells of the small intestinal epithelium, can upregulate the expression of BMP-4 in the fibroblasts near the stem cells, although it has not yet been demonstrated in the mammalian adult intestine. 
Interestingly, in the human intestine, Shh expression has been shown to be upregulated in the neoplastic or inflammatory intestine when the stem cells compensate for the epithelial damage $[27,28]$. Taken together, it seems likely that Shh expression in the stem cells is the first key step to the formation of the cell-renewable epithelium and makes the microenvironment adequate for the stem cell niche by upregulating the expression of its target genes such as BMP-4 in the subepithelial fibroblasts.

In the embryonic gut, it has been shown that BMP-4 represses the proliferating activity of mesenchymal cells [29], although its function in the endoderm and/or epithelium is still less defined. In the Xenopus model, our culture studies have shown that BMP-4 protein also represses the proliferating activity of the connective tissue cells [18] as well as in the embryonic gut. In addition, we demonstrated that BMP- 4 protein promotes the differentiation of descendants of the stem cells into the absorptive epithelium expressing intestinal fatty acid-binding protein, a marker for the differentiated absorptive cells. On the other hand, BMP-4 deficiency, which is caused by adding excessive chordin, an antagonist of BMP-4, decreases the total number of epithelial stem cells [18]. This result suggests a possibility that a certain amount of BMP-4 may be necessary for the survival and/or the selfrenewal of the epithelial stem cells in the small intestine, as proposed in other organs such as the ovary [38] and embryonic stem cells [30, 31]. In addition, in the Xenopus intestine, BMP-1 has also been identified as a TH response gene. The expression of BMP-1 is upregulated by TH and is localized in the connective tissue as that of BMP-4, suggesting that BMP- 4 activity in the small intestine can be regionally regulated by BMP-1 through chordin as proposed during organogenesis of the early embryos [32].

In contrast to the BMP-4 function, our culture study using the amphibian model has shown that Shh protein promotes the proliferating activity of the connective tissue. In addition, Shh causes anomalies of the intestinal epithelial structure such as the closure of the lumen, suggesting the disruption of the radial axis [23]. Therefore, in this animal model, Shh expression and Shh-induced BMP-4 expression play key roles as the epithelial and connective tissue signaling molecules, respectively, in the development of the adult intestinal epithelium that undergoes cell renewal along the radial axis. To clarify the entire process of stem cell development along the radial axis, future studies should be directed to more precise analysis of the function of each member of this signaling pathway and its interactions with other signaling pathways such as the Wnt and Notch pathways.

\section{Conclusion}

The epithelium of the adult small intestine is a fast-renewing tissue, where all of the epithelial cells originate from the stem cells localized near the bottom of the crypt and differentiate as they migrate along the crypt-villus axis. This axis is established as the radial axis during development and is maintained throughout adulthood to enable the epithelial cell renewal. Disruption of the axis leads to various developmental anomalies and diseases such as cancer. Thus, the clarification of the molecular mechanisms regulating the radial axis is important from the clinical viewpoint and is urgently needed for the stem cell therapies. The amphibian intestinal remodeling, where the radial axis analogous to the mammalian cryptvillus axis can be experimentally established by the inductive action of $\mathrm{TH}$, serves as an excellent and unique model for understanding the molecular aspects of the radial axis conserved across the animal species. Functional studies carried out on $\mathrm{TH}$ response genes have shown a growing body of evidence that the Shh/BMP-4 signaling pathway plays key roles in the control of the radial axis through epithelial-connective tissue interactions. Recent progress in transgenic frog technology $[33,34]$ and gene transfer techniques in vitro [35] will enable more direct functional analysis of $\mathrm{TH}$ response genes, leading to the clarification of the whole network of signaling pathways controlling the radial axis. Interestingly, in the human intestine, structural and physiological maturation occurs at birth, when the endogenous TH levels transiently increase similar to those during amphibian metamorphosis $[36,37]$. Studies with the amphibian intestinal model would give us clues for the full understanding of molecular mechanisms underlying the crypt-villus axis in the human intestine, even if they are more evolutionarily complicated than those in this animal model.

\section{Acknowledgements}

We would like to express our gratitude to Dr. Yun-Bo Shi, National Institutes of Health, USA, for his valuable advice and collaboration. This research was supported in part by JSPS Grantsin-Aid for Scientific Research (C) (to A.I.-O.).

\section{Disclosure Statement}

This research was partially supported by JSPS Grants-in-Aid for Scientific Research (C), Japan. 


\section{References}

1 Bjerknes M, Cheng H: The stem-cell zone of the small intestinal epithelium. III. Evidence from columnar, enteroendocrine, and mucous cells in the adult mouse. Am J Anat 1981;160:77-91.

-2 Crosnier C, Stamataki D, Lewis J: Organizing cell renewal in the intestine: stem cells, signals and combinatorial control. Nat Rev Genet 2006;7:349-359.

-3 Roberts DJ: Molecular mechanisms of development of the gastrointestinal tract. Dev Dyn 2000;219:109-120.

-4 Potten CS: Stem cells in gastrointestinal epithelium: numbers, characteristics and death. Philos Trans R Soc Lond B Biol Sci 1998;353: 821-830.

5 Dessimoz J, Opoka R, Kordich JJ, GrapinBotton A, Wells JM: FGF signaling is necessary for establishing gut tube domains along the anterior-posterior axis in vivo. Mech Dev 2006; 123:42-55.

6 Mills JC, Gordon JI: The intestinal stem cell niche: there grows the neighborhood. Proc Natl Acad Sci USA 2001;98:12334-12336.

$\checkmark 7$ Moore KA, Lemischka IR: Stem cells and their niches. Science 2006;311:1880-1885.

-8 Powell DW, Mifflin RC, Valentich JD, Crowe SE, Saada JI, West AB: Myofibroblasts. II. Intestinal subepithelial myofibroblasts. Am J Physiol 1999;277:C183-C201.

-9 Andoh A, Bamba S, Fujiyama Y, Brittan M Wright NA: Colonic subepithelial myofibroblasts in mucosal inflammation and repair: contribution of bone marrow-derived stem cells to the gut regenerative response. J Gastroenterol 2005;40:1089-1099.

10 Paris F, Fuks Z, Kang A, Capodieci P, Juan G, Ehleiter D, Haimovitz-Friedman A, Cordon-Cardo C, Kolesnick R: Endothelial apoptosis as the primary lesion initiating intestinal radiation damage in mice. Science 2001;293:293-297.

11 Bjerknes M, Cheng H: Modulation of specific intestinal epithelial progenitors by enteric neurons. Proc Natl Acad Sci USA 2001;98: 12497-12502.

12 Sancho E, Batlle E, Clevers H: Signaling pathways in intestinal development and cancer. Annu Rev Cell Dev Biol 2004;20:695723.

13 Booth C, Brady G, Potten CS: Crowd control in the crypt. Nat Med 2002;8:1360-1361.

14 Van Den Brink GR, de Santa Barbara P, Roberts DJ: Development: epithelial cell differentiation - a matter of choice. Science 2001; 294:2115-2116.

15 Shi Y-B: Amphibian Metamorphosis. From Morphology to Molecular Biology. New York, Wiley \& Sons Inc, 1999.
16 Ishizuya-Oka A, Shimizu K, Sakakibara S, Okano H, Ueda S: Thyroid hormone-upregulated expression of Musashi-1 is specific for progenitor cells of the adult epithelium during amphibian gastrointestinal remodeling. J Cell Sci 2003;116:3157-3164.

17 Shi YB, Ishizuya-Oka A: Biphasic intestinal development in amphibians: embryogenesis and remodeling during metamorphosis. Curr Top Dev Biol 1996;32:205-235.

18 Ishizuya-Oka A, Hasebe T, Shimizu K, Suzuki K, Ueda S: Shh/BMP-4 signaling pathway is essential for intestinal epithelial development during Xenopus larval-to-adult remodeling. Dev Dyn 2006;235:3240-3249.

19 De Santa Barbara P, van den Brink GR, Roberts DJ: Development and differentiation of the intestinal epithelium. Cell Mol Life Sci 2003;60:1322-1332.

20 He XC, Zhang J, Tong WG, Tawfik O, Ross J, Scoville DH, Tian Q, Zeng X, He X, Wiedemann LM, Mishina Y, Li L: BMP signaling inhibits intestinal stem cell self-renewal through suppression of Wnt-beta-catenin signaling. Nat Genet 2004;36:1117-1121.

21 Haramis AP, Begthel H, van den Born M, van Es J, Jonkheer S, Offerhaus GJ, Clevers $\mathrm{H}$ : De novo crypt formation and juvenile polyposis on BMP inhibition in mouse intestine. Science 2004;303:1684-1686.

22 De Santa Barbara P, van den Brink GR, Roberts DJ: Molecular etiology of gut malformations and diseases. Am J Med Genet 2002; 115:221-230.

23 Ishizuya-Oka A, Ueda S, Inokuchi T, Amano T, Damjanovski S, Stolow M, Shi YB: Thyroid hormone-induced expression of sonic hedgehog correlates with adult epithelial development during remodeling of the Xenopus stomach and intestine. Differentiation 2001;69:27-37.

-24 Roberts DJ, Johnson RL, Burke AC, Nelson CE, Morgan BA, Tabin C: Sonic hedgehog is an endodermal signal inducing Bmp-4 and Hox genes during induction and regionalization of the chick hindgut. Development 1995;121:3163-3174.

25 Sukegawa A, Narita T, Kameda T, Saitoh K, Nohno T, Iba H, Yasugi S, Fukuda K: The concentric structure of the developing gut is regulated by Sonic hedgehog derived from endodermal epithelium. Development 2000; 127:1971-1980.

26 Marigo V, Roberts DJ, Lee SM, Tsukurov O, Levi T, Gastier JM, Epstein DJ, Gilbert DJ, Copeland NG, Seidman CE, et al: Cloning, expression, and chromosomal location of SHH and IHH: two human homologues of the Drosophila segment polarity gene hedgehog. Genomics 1995;28:44-51.
-27 Berman DM, Karhadkar SS, Maitra A, Montes De Oca R, Gerstenblith MR, Briggs K, Parker AR, Shimada Y, Eshleman JR, Watkins DN, Beachy PA: Widespread requirement for Hedgehog ligand stimulation in growth of digestive tract tumours. Nature 2003;425:846-851.

28 Nielsen CM, Williams J, van den Brink GR, Lauwers GY, Roberts DJ: Hh pathway expression in human gut tissues and in inflammatory gut diseases. Lab Invest 2004;84: 1631-1642.

-29 Batts LE, Polk DB, Dubois RN, Kulessa H: Bmp signaling is required for intestinal growth and morphogenesis. Dev Dyn 2006; 235:1563-1570.

30 Fujiwara T, Dunn NR, Hogan BL: Bone morphogenetic protein 4 in the extraembryonic mesoderm is required for allantois development and the localization and survival of primordial germ cells in the mouse. Proc Natl Acad Sci USA 2001;98:13739-13744.

31 Qi X, Li TG, Hao J, Hu J, Wang J, Simmons H, Miura S, Mishina Y, Zhao GQ: BMP4 supports self-renewal of embryonic stem cells by inhibiting mitogen-activated protein kinase pathways. Proc Natl Acad Sci USA 2004;101: 6027-6032.

32 Wardle FC, Welch JV, Dale L: Bone morphogenetic protein 1 regulates dorsal-ventral patterning in early Xenopus embryos by degrading chordin, a BMP4 antagonist. Mech Dev 1999;86:75-85.

-33 Fu L, Buchholz D, Shi YB: Novel double promoter approach for identification of transgenic animals: a tool for in vivo analysis of gene function and development of genebased therapies. Mol Reprod Dev 2002;62: 470-476.

-34 Buchholz DR, Tomita A, Fu L, Paul BD, Shi YB: Transgenic analysis reveals that thyroid hormone receptor is sufficient to mediate the thyroid hormone signal in frog metamorphosis. Mol Cell Biol 2004;24:9026-9037.

35 Ikuzawa M, Shimizu K, Yasumasu S, Iuchi I, Shi YB, Ishizuya-Oka A: Thyroid hormoneinduced expression of a bZip-containing transcription factor activates epithelial cell proliferation during Xenopus larval-to-adult intestinal remodeling. Dev Genes Evol 2006; 216:109-118.

36 Lebenthal E: Human Gastrointestinal Development. New York, Raven Press, 1989.

37 Henning SJ: Postnatal development: coordination of feeding, digestion, and metabolism. Am J Physiol 1981;241:G199-G214. 